\title{
A Study on Interpreter's Intercultural Awareness
}

\author{
Mianmian Cai \\ Xiamen University Tan Kah Kee College \\ Zhangzhou, China
}

\begin{abstract}
As a basic communication tool, interpreting plays an increasingly significant role in intercultural communication. Interpreting is not only the expression of linguistic information but also the exchange of cultures. Therefore, great emphasis should be placed on raising interpreters' intercultural awareness. Based on explaining Hanvey's Statement of Four Levels of Intercultural Awareness and case study, the author hopes to demonstrate the importance of cultivating a sharp intercultural awareness.
\end{abstract}

Keywords-interpreting; intercultural awareness; communication

\section{INTRODUCTION}

Nord defines "communication as being carried out by means of signs, which are verbal or nonverbal behavior associated with a concept or meaning by the producer, the receiver, or both" [1]. In essence, communication is exchange of meanings between the participants. As Nida states, translation is communication in nature [2]. So interpretation, a kind of oral translation, is oral face-to-face communicating. It functions as an inseparable tool for the successful communication between different language speakers. Interpreting is designed to serve the people who want to achieve communication across barriers of language and culture. Knowledge of two or more languages does not make one a qualified interpreter. To learn the speaker's intention, a point cannot be forgotten that interpretation, at the same time, is cross-cultural communication. Interpretation can be understood correctly under the sociocultural context in which they appear. Therefore, interpreters shall "play a social role" so as to "fulfill a function allotted by a community - to the activity, its practitioners and their products - in a way which is deemed appropriate in its own terms of reference" [3]. Interpretation is the conformity of language cognition and culture cognition.

\section{CULTURE RETURN OF INTERPRETATION STUDY}

It is all known that there are differences in values, economics, cultures, social systems among different countries, which cause people to adopt different attitudes towards the same situation. Due to the social and ethnological properties of culture, conventions and values unique to a culture may turn out to be completely incomprehensible or unacceptable to another culture. For example, it is a traditional virtue for Chinese people to give their seats to the elders on a crowded bus or subway to show their concern and respect for the elders. Whereas people from western countries may regard this behavior as impolite and humiliating because being given seats implies that they are not strong, capable or independent enough. Consequently, a good intention may turn out to be hostility if you don't know their culture. Another example is that when two Chinese run into each other, they often greet each other by asking "Have you had your meal?" or "Where are you going?" to express their care for other people; actually they do not really want to know the answer to the questions. But such salutation might be considered by westerners as intruding on their privacy because people are not entitled to ask question about others' personal schedule. Cultural differences exist in daily communication, not to mention at an international press conference, where the impact of cultural differences tends to be magnified. Thus it is delightful to see that more and more researchers are paying attention to cultural factors in interpretation study. They reevaluate the influence of cognition, values and beliefs on interpretation. The cultural return in interpretation study is bound to yield illuminative perspectives on such issues as the relations among thinking, culture and language, the relations between the interpreter and the audience, as well as the decisive factors influencing interpretation quality [4]

During interpretation, interpreters have the most direct access to different cultures; therefore, they should convey both parties' intentions quickly and accurately, so as to facilitate the conversation and fulfill his duty. Interpreters' lack of knowledge of cultural differences can result in indigestible interpretation, causing misunderstanding and failure of communication. Generally speaking, the reasons for cultural barriers in interpretation can be classified into the following four categories:

\section{A. Differences in Cultural Images}

Cultural images are cognitive patterns established and accepted through common practice. As cultural symbols, they contain rich meanings and extensive associations, embodying the particular history and culture. Inaccurate delivery of culture images can result in misconception. [5]

Take the word "dragon (龙)" for instance: it is an auspicious symbol for Chinese people. In the ancient time, people worshiped dragon to beg for rain. And the Chinese feudal emperors were often referred to as sons of dragons (龙 子), wearing clothes with designs of dragons (龙袍). And also the Chinese all proudly regard themselves as descendants of the dragon (龙的传人). However, in Western people's minds, the dragon is some imaginary evil, fierce and cruel monster with a large tail and wings and claws, breathing out fire and 
smoke. It is an evil symbol. So, when interpreters encounter such phrases as “望子成龙”, they should take into consideration the different connotations of the word "dragon (龙)". It is not recommended to translate the expression literally into "hoping one's children will become a dragon". Instead, it is preferable to add necessary explanation so as to offset the differences of cultural images. Possible translations include: hope one's children will have a bright future or have great ambitions for one's child.

\section{B. Differences in Way of Thinking and Cognition}

The way that people perceive and cognize the world they live in is diverse; hence the difference in their expression of the same thing. The different descriptions of date, location, orientation and metrology, etc reflect the different ways of thinking between the Chinese and the westerners. For instance, such words to indicate directions as “东北、西北、东 南、西南” should be interpreted respectively as "northeast, northwest, southeast, and southwest". When it comes to address, the Chinese like to put big units before small ones whereas the westerners are used to the reverse order. As a matter of fact, this difference is also explicit when composing articles. Chinese people tend to describe the background at great length before getting right to the point while westerners are more used to come straight to the point at the beginning and then add details. Take grammar for example, in the English language, there can be only one main clause to stress the key point, with clauses for supplementary information of time, condition, etc., such as attributive clause, adverbial clause. Numbers are especially difficult to interpret. “万” in Chinese should be transformed into "ten thousand" and "亿" is equivalent to "hundred million". This distinction is particularly brain-consuming and requires intensified training.

\section{Differences in Human Values}

According to M. Rokeach, Human Values are the internal reference points that all people use to formulate attitudes and opinions, and that by measuring the relative ranking of these values one could predict a wide variety of behavior, including political affiliation and religious belief [6]. It is the in-depth component of culture. The Chinese culture values collectivism and therefore appreciates modesty. On the contrary, the western culture advocates individualism and emphasizes self-value. Therefore, when receiving a compliment, Chinese people tend to be modest and owe the success to the whole group. The westerners, instead, say "thank you" directly in return for the compliment. In addition, Chinese people's emphasis on modesty can also be reflected on the proverbs "Tall trees catch much wind" and "Fame portends troubles". Thus it is considered a virtue to keep a low profile. One typical example is parents' reaction when others praise their children for being smart, wellmannered, etc. Many Chinese parents would, out of modesty, decline the compliment and instead complain about their children's naughtiness or other bad habits as a way of keeping a low profile. Besides, Chinese people attach great importance to consanguinity and hierarchy due to the history of feudalistic society which existed for more than two thousand years. For that reason, the Chinese appellation is very strict and detailed. By comparison, the westerners are more accustomed to addressing each other by their names, which shows their pursuit of equality.

\section{Differences in Classical Literature Allusions}

Both Chinese and English contain varied and colorful idioms and proverbs originated from fables or literature, characterized by specific names, time and locations. Without the knowledge of the relevant background information, if interpreters adopt the literal interpretation of such idioms and proverbs, the target audience will undoubtedly find it difficult to comprehend and may be at a loss. Therefore, it is preferable to add necessary explanation to the interpretation.

Take the idiom “东施效慗” for instance. Back in the Spring and Autumn period, there was a beautiful and elegant girl named Xi shi. She had a pain in her bosom so she had a frown on her face every now and then. She was so charming that even her frown seemed attractive to the people around. An ill-looking girl named Dong shi was jealous of Xi Shi's attractiveness and firmly believed that people adore $\mathrm{Xi}$ shi because of her frown. Therefore Dong shi imitated Xi Shi's frown. The consequences were devastating; people avoided Dong shi because she had become much uglier than before. If “东施效晸” is interpreted literally, the audience will certainly be at a loss; if it is interpreted otherwise, such as "blind imitation with ludicrous effects", its derivation will be ignored. A compromise is to adopt the strategy of free interpretation and add explanatory notes. In this way, interpreter can make themselves understood while ensure the introduction of culture.

\section{ENLIGHTENMENT OF CULTURAL FACTORS ON INTERPRETERS' PERFORMANCE}

Interpreting activity is indeed a cultural exchange activity. With an examination of the factors for cultural barriers in interpretation, the author suggests that interpreters should raise their intercultural awareness so as to shorten the gap between two cultures.

\section{A. Hanvey's Statement of Four Levels of Intercultural Awareness}

In order to obtain intercultural awareness, first of all, we need to have a general idea of Hanvey's statement of four levels of intercultural awareness. Hanvey noted [7]:

At level I, a person might know some practice in other cultures, for instance, the fact that Japanese are exaggerated in their politeness. At level II, a person knows, through either direct or secondhand experience, of cultural traits that significantly contrast with one's own practices. At level III, a person might know, for example, that the really distinctive aspect of the Japanese social hierarchy has nothing to do with the forms of politeness but rather exists in the keen sense of mutual obligation between superior and inferior. At level IV, a person has the awareness of how another culture feels from the standpoint of the insider. This is termed "empathy" by people [8]. Interpreters should try to reach the level 4. The higher their intercultural awareness is, the better 
their interpreting will be. Hanvey placed great emphasis on interpreter's intercultural awareness. His theory provides a theoretical foundation for cultivating intercultural awareness. For interpreters, intercultural awareness refers to interpreters' cognitive criterion and adjustment measures formed consciously and unconsciously during intercultural communication, including unique way of thinking, well judgment and acute sensitivity to cultural factors peculiar to interpreters. A sharp intercultural awareness is of great help for interpreters in that they can skillfully and properly deliver the interpretation, without being influenced by cultural differences. What' s more, interpreters can offset pragmatic failures during the interpreting process and facilitate the intercultural communication.

\section{B. The Importance of Intercultural Awareness}

In a certain sense, the difficulties of interpreting lie much more in the cultural aspect than in the language aspect. Prof. $\mathrm{Hu}$ Wenzhong once carried out an investigation to find out both the students' and teachers' views on intercultural awareness. Among the 28 teacher respondents, who are either native English speakers or specialists in cultural exchange, 26 (92\%) thought that there was a cultural gap between their Chinese students and themselves and all of them thought awareness of cultural differences should be made a goal in teaching. $15(53 \%)$ of them said that "cultural mistakes" (that is, language and behavior which is inappropriate or unacceptable to most native English speakers) made them more uncomfortable than grammatical mistakes. Most of the "cultural mistakes" are reported in socializing (60\%) and only a quarter of them in written work. Of the student respondents, 62 (97\%) thought that there was a cultural gap between native English speakers and themselves. 61(95\%) held that cultural awareness should be made one of the goals in teaching [8].

According to the above investigation, we can conclude that cultural intercultural awareness is one of the essential competences of interpreters, without which the interpretermediated intercultural communication activity cannot be conducted successfully. Equipped with this intercultural awareness and intercultural sensitivity, interpreters can overcome cultural barriers they encounter during interpretation. Even when they are not occupied in interpretation, this intercultural sense will serve as a guide in their off-hour study for self-improvement. Intercultural awareness exerts a direct influence on the quality of interpretation. Meanwhile, it is also an important criterion to judge whether a language learner can meet the demands for a qualified interpreter [9].

\section{To Raise Intercultural Awareness}

Generally speaking, if people want to communicate with each other, they should share the same language system and cultural background. On interpretation occasions, the speaker and the audience have little in common in terms of language system and cultural background. Thus interpreters serve as "mediators" [10], because they "have not only a bilingual ability, but also a bicultural vision. They mediate between cultures, seeking to overcome those incompatibilities which stand in the way of transfer of meaning."

To raise intercultural awareness, interpreters should make great efforts to acquire general erudition and intimate familiarity with both cultures. They should take every means available to enrich their cultural knowledge. They can read books and attend lectures on the topic of cultural differences, watch films and videotapes about the customs and habits of foreign countries, or they can directly make contact with native speakers. Of course, the most effective way is the direct exposure to the alien culture. The ultimate goal is to acquire true empathy, because the difficulty lies in the "hidden culture". Wang Zuoliang, a noted linguist in China, believed that "a translator should be a cultural person in every sense. Undoubtedly he should have a good command of two languages. However, without the knowledge of involved culture, no one can truly master a language. He should not just have some acquaintance with the culture, instead, he should know the past and present of the people, including history, development, habits and customs, emotions, philosophy, scientific achievements, politics and social organizations, etc. The more he knows about the target culture, the better he incorporates into the target culture. At the same time, the interpreter should learn about his own culture. What's more, he should constantly draw a comparison between these two cultures. When he searches for equivalence, he should make comparisons because real equivalence should be achieved in every respect, including meaning, effect, emotions, and so on. " [11]

The society develops with each passing day; new words and phrases mushroom. Interpreters should pay attention to these changes, politically, economically and socially. Interpreters can visit the major domestic foreign websites, China Daily and Shanghai Daily, to follow closely the state affairs. The news is updated on a daily basis. In addition, the author would like to recommend the "buzzword" column of the website of Shanghai Daily, where users have access to the latest word and phrases in China, both in Chinese and in English, such as residue-free vegetable (无公害蔬菜), topgrade fakes (A 货), and cheaper-meal hunter (蹭饭族). If interpreters accumulate these new expressions, they can use as references and save a lot of trouble figuring out the equivalent words when they encounter them.

Therefore, interpreters are required to increase their intercultural awareness as well as enrich their cultural knowledge so as to aid this intercultural communicative activity. What the interpreter deals with are not two languages, but two cultures.

\section{EXAMPLE ANALYSIS}

Once interpreters have this intercultural awareness, they can exempt themselves from the negative influence of cultural differences and thus deliver the information properly and accurately. Besides, interpreters with intercultural awareness tend to take into consideration the need for communication and supplement speakers' slip of tongue, if any, in order that successful intercultural communication can be accomplished. 
The author selects some examples from the press conference of China's National People's Conference on 18 Mar, 2008, where the respectable premier Wen Jiabao answered questions raised by journalists from home and abroad. Premier Wen Jiabao is well known for his erudition and eloquence; he often quotes copiously from ancient poems and literature to make his answers more convincing and persuasive. This press conference is no exception. It is hard to imagine how an interpreter with no intercultural awareness can convey the information to the audience as vividly and powerfully as the source information. Undoubtedly, the interpreter at this press conference has done a marvelous job. His excellent interpreting skills and sharp intercultural awareness can be used for our reference.

温总理: 5 年已经过去了, 行事见于当时, 是非公于后世。历史是 人民创造的，也是人民书写的。一个领导者应该把眼睛盯住前方，把 握现在, 思考未来。……5 年前, 我曾面对大家立过誓言, 苟利国家 生死以, 岂因祸福趋避之。今天我还想加上一句话, 就是天变不足 畏, 祖宗不足法, 人言不足恤。

Interpreter: Five years has passed. What one does now will be fairly judged by history. History is created by people and written by people. As a leader, his eyes should be on the way ahead and his energy should be focused on the present and at the same time he should be thinking of the future... five years ago, in front of a similar audience, I made a promise, which is also my motto, that one should uphold his country's interest with his life; he should not do things just to pursue his personal gains and he should not evade his responsibilities for fear of personal loss. Today, I'd like to add a few more lines. One should not fear changes under the heaven, and one should not blindly follow old conventions and one should not be deterred by complaints of others.

Premier Wen Jiabao's remarks contain three quotations which are of Chinese characteristics: they match in sound, sense and structure but they are not connected by conjunctions. The interpreter was not bounded by the form of Chinese; instead, he added subjects to each quotation with "one" and "he" and supplemented the conjunction "and" when necessary. Besides, the interpreter precisely paraphrased the last quotation. In this way, the profound citation was made easier to understand by the audience, especially by foreign journalists. The interpreter displayed sensitive intercultural awareness.

温总理: 我一直很重视两向话: 一向话来自《诗经》, 一向话来自 《诗品》, 就是周虽旧邦, 其命惟新; 如将不尽, 与古为新。

Interpreter: I myself value greatly the following two lines quoted from Book of Songs and Book by the Name of the Character of Poems. One is that although Zhou was an ancient state, it had a reform mission. The other is that only innovation could ensure the growth and vitality of a nation.

Book of Songs is the earliest general collection of ancient Chinese poems and Book by the Name of the Character of Poems is an aesthetic works of literature. However, the majority of the target audience was unacquainted with these two literature works. When it comes to literature, it is better for interpreters to interpret the title according to the generally accepted translation. The quotations were concise and succinct, carrying rich connotations. Given the context and the environment, the interpreter chose to explain the literal meaning, in order to shorten the cultural gap as much as possible.

温总理: 我常常一边上网, 脑子里就想一段话, 就是 “民之所忧, 我之所思; 民之所思，我之所行”。

Interpreter: Sometimes when I was surfing the internet, I was also pondering over the following lines: "What people's concerned about is what preoccupies my mind, and what preoccupies the minds of the people is what I need to address."

This quotation is another four-syllable structure of succinct style, which is quite typical in the Chinese language. Both the sound and the structure match. It is hard to achieve the same structure as the original sentence. However, the interpreter managed to deliver the information in a concise way based on the whole meaning; at the same time, the interpreter adopted parataxis to reproduce the rhetorical effect.

From these examples, we can conclude that it is impossible to find a completely equal counterpart in the target language to substitute for each original word. Absolute linguistic equivalence does not work in interpretation, for blind pursuit of linguistic equivalence is bound to bring the on-going communication nowhere but deadlock. The aim of interpreting is not to establish linguistic equivalence between two languages, but to communicate the meanings of a speech being heard. Apart from accuracy and clarity, the interpreter should flexibly make some changes in expression in terms of the hearer's culture and custom. In many cases, to narrow the cultural gap is important for an appropriate interpretation

\section{CONCLUSION}

Based on the above case study, we can draw the conclusion that interpreting is a skill as well as an art, which requires interpreters to master sharp and sensitive intercultural awareness so as to transcend the barriers of language and culture. In the communication process, interpreter works as "a mediator standing at the center of the dynamic process of communication between the SL speaker and TL audience" [10]. To find the optimal relevance from the source context, interpreters need to read extensively to enrich their knowledge of culture, become familiar with the thinking way of the people of the source culture and manage to offset the difference of thinking ways between two cultures. Through consistent practice, interpreters will gradually become inter-culturally competent. To study and respect other cultures, to transcend the cultural barriers and to eliminate misinterpretation caused by cultural difference are the important qualities to guarantee the success of this complicated and challenging activity. After all, interpretation is the conformity of language cognition and culture cognition.

\section{REFERENCES}

[1] Nord Christiane, Translating as a Purposeful Activity: Functionalist Approaches Explained. Shanghai: Shanghai Foreign Language Education Press, 2001. 
[2] Nida Eugene, Language, Culture and Translating. Shanghai: Shanghai Foreign Language Education Press, 1993.

[3] Toury, G, Descriptive Translation Studies-and Beyond. Shanghai: Shanghai Foreign Language Education Press, 2001

[4] Zhao Junfeng, Jiang Nan, "On Interpreters' Intercultural Awareness" in Chinese Science \& Technology Translators Journal, vol. 5, p29-31, 1998.

[5] Lin Xinhua, Literature Translation and Semantic Cognition. Fuzhou: Fujian People's Publishing House, 2005.

[6] Milton Rokeach, The Nature of Human Values. New York: Free Press, 1973.

[7] Hanvey, R., Toward Internationalism: Readings in Cross-cultural Communication. Cambridge: Newbury House Publishers, 1979.

[8] Hu Wenzhong, Intercultural communication and english study. Shanghai: Shanghai Translation Publishing House, 1988.

[9] Xu Lina, "On Interpreters' Intercultural Awarenss" in Consume Guide, vol. 4, p17.

[10] Hatim, B \& Mason, I. Discourse and the Translator. Shanghai: Shanghai Foreign Language Education Press, 2001. 